\title{
A Unified E- Government Service - An Essential Component of a Smart City
}

\author{
Nada Alrehaili ${ }^{1}$, Yasmeen Almutairi ${ }^{2}$, Manal Alasmari ${ }^{3}$, Abeer Assiry ${ }^{4}$, Dr. Maram Meccawy ${ }^{5}$ \\ Dept of Information Systems, Faculty of Computing and Information Technology, Jeddah, Kingdom of Saudi Arabia ${ }^{1-5}$
}

\begin{abstract}
The concept of a smart city is relatively new and it has not been widely applied in Saudi Arabia. The Saudi government aims to launch a number of smart cities projects to improve the quality of life for its citizens and to fulfill its vision for 2030. This paper, proposes a new model, which provides e-government services as part of a solution for a smart city. It presents a unified one-stop shop for all governmental services instead of being separating among various applications or websites. The paper provides an overview of the application known as E-Gov, discusses the opportunities and concludes with some of the implementation barriers.
\end{abstract}

Keywords: E-Gov, e-government, Smart city, Smart government, Saudi Arabia, Services.

\section{INTRODUCTION}

Since the concept of smart cities, from a scientific prospective, is new, there is no universally agreed upon definition of it. But generally, the smart city concept means the city that use many smart factors of Information and Communication Technology to increase the city's sustainable growth city functions, to increase the life quality [1]. It creates an innovation network between cities and try to develop better e-services to citizens. Smart city projects work to provide better e-government and e-services to improve personalized and user-oriented services, as smart cities mean smart services [2].One of the most important features of smart cities is to make governance citizen-friendly and cost effective increasingly depending on online services to get more accountability and transparency, especially using mobiles to reduce services cost and providing services without having to go to municipal offices [3]. Simply, e-government is the use of information and communication technologies (ICTs) to improve the tasks of public sector organizations, more especially the delivery of government services to the citizens, employees and the business partners. E-government has many benefits such as: reduce administrative costs, provide better levels of service with new kinds, attract overseas investors and fraud controlling [4].

Smart city applications are also important part of any smart city, it composes the digital layer of smart cities which is a fundamental tier of smart cities. They depend on a series of information, communication and programming technologies. Smart application can be defined as a software that empower the city, governments, community and citizens to collaboratively address city challenges in more efficient and intelligent or smart ways. (This definition is not for all smart city application which may specified for some new digital hardware) [5]. Smart Cities applications cover a range of life aspects including helping people with disabilities, next generation art, vehicles parking, web, real time news and sensors update, citizen's participation, healthcare services, citizen involvement and individual e-services.

\section{E-GOVERNMENT APPLICATION IN SAUDI ARABIA, AN OVERVIEW}

One of greatest problems faced any one has dealing with government sectors is the complexity and its relative sectors. Saudi government has about 28 ministries and each of them has different agents. And even for simple matter like registering child birth, setting up a new business or buying a house, multiple agencies need to be visited hence multiple forms may be required, the citizen need to communicate with each of them and the citizen need to repeat their "story" for each organisation at each point of contact.

Nowadays, with technology revolution individuals expect a better and faster services from their government, with greater effectiveness without complexity. Lastly, some Saudi ministries enhanced to finish their transactions online or partly online and they create some private application for each of them. But some other ministries still yet do most of the work in traditional manner. Ministry of justice for instance still need to create application to facilitates its services (for example court service, justice attorney and take appointments) and communication with individuals.

Nowadays, Saudi government is striving to use the Internet to link its institutions and ministries to each other and therefore provide their various services to the public in general, put the information at the disposal of individuals to create a clear relationship characterized by speed and accuracy, aimed at improving the quality of performance.

Here we mention some applications that provide different services by Saudi government to citizens. The first one is application of electronic services from the Interior Ministry known as Absher [6], which is used to accomplish the procedures and transactions of passports or National Identification cards issuing and renewals and check traffic fines 


\section{IARJSET

from anywhere at anytime. The second one is citizen services application by Water \& Electricity Ministry [7]. It allows citizens to inquire about various services such as electricity and water bills and well drilling licenses. Another popular service application is MySTC [8], which is an application developed by Saudi Telecommunication Company to give citizens the ability to do their operations easily, like viewing the bills and pay them, recharge prepaid numbers and transfer amounts between them, subscribe and unsubscribe in packages and services, and a lot more features that saves people time and effort.

In addition, there is an important application provided by the Ministry of Health in Saudi Arabia official, which provides services such as ministry news, world health days and different E-Services as exchanging some ministry orders and vaccinations remainder service [9]. The Ministry of Education (MoE) provides its services electronically such as The Noor System [10], which is a comprehensive and integrated educational learning system. It relies on the most advanced technology in the field of educational management, covering all schools belonging to the Ministry of Education. Safeer [11], is another e-service provided by MoE. It is an electronic portal designed to serve students in the abroad by facilitating the procedures on them and saving their time and effort. Safeer offers many services for students such as personal data modification, ticket request, application follow-up service, etc. Moreover, there are many services provided by the ministry like Maqbool, Faris and Ien [12]. Globally, the United Kingdom is the leader of e-government services. It uses the technology to better serve their citizens, recent research claims that the UK may become the world's leading "e-Government" if it can meet anticipated growth in demand for internet accessibility [13].

\section{A UNIFIED E-GOVERNMENTAL SOLUTION FOR JEDDAH AS A SMART CITY}

In order to enhance automated governmental services to be accessed anytime anywhere is to create a mobile based model that combines all the government services via one gate instead of their separation by various application and sites. It is a one-stop shop for citizens and residents. Users of this application can access all the services of the government such as the Ministry of justice services, Electricity bills, Telecom Companies services and Ministry of Interior services, easily from one application and all of transaction are recorded and it can be viewed at any point of time. Using the mobile based application in day to day activities can facilitate all complexity between different ministries because it is easily updated to remote database server immediately.

The proposed unified model can provide many advantages to Saudi citizen such as time saving, secured environment, prevent any possible bureaucracy in government transaction, and increase work efficiency. Our application for the proposed model contains initially five government services:

- First: ministry of interior services includes query health insurance, query Hajj eligibility, Bayanati service, book an appointment, report missing documents, Taqdeer service and request replacement document.

- Second: all service of ministry of justice include Court service like fill forms and take number of request to follow up, Also justice attorney and all other ministry services.

- Third: Electricity Company service such as complains, bill service and electricity service connection.

- Forth: ministry of environment and water services include directorates of water services and bills.

- Fifth: telecom companies' service includes devices services, printing invoices, payment and complains.

This application links all government services, once the user enters the unique ID number and the password. it will show him/her personalized information and a list of all the services of the aforementioned ministries. The citizens can also submit complaints by taking a picture of the problem or writing a message it in the complaint area. They can also receive notifications of invoices, updated dates, or any latest news in each ministry. They can also share comments, tips, and news with other citizens in the comment place. Users will be able to complete many transactions by using a single application. Moreover, since the users are the general public, which means people from different ages, backgrounds, level of education and different walks of life, the model has to be implemented a usable and accessible application for all. The application provides users with a familiar and simple environment where the environment contains buttons, menus and text are all familiar to the user so they can focus on the application itself and not on the mechanism of the control buttons. In addition, the application should provide the information on time, it will be available 24/7, make the government business easy, simple and more efficient thereby reducing the costs of government procedures. Moreover, it will help to ensure the transparency in government work; employees 'workload and achievements would be monitored in order to reach the targeted Service Level Agreement (SLA).

\section{E-GOV IMPLEMENTATION}

The main purpose of this application is to facilitate and streamline the operations of citizens by creating a single platform that combines some government services that can be installed on the mobile devices. Firstly, we use inspira Application to make primary design of GUI of E-Gov application. 
Here we provide an implementation mockup a model. The fully function application needs to be connected with the governments ministries database and need to pass in agile development process and as it is a governmental application it should be a high-quality application with high level of security and privacy. Here we preferred to use Xcode in programming. Xcode is an integrated development environment for mac operating systems containing a suite software development tools developed by Apple.

\section{DISCUSSION: OPPORTUNITIES AND BARRIERS}

\section{A. Opportunity of the E-Gov application}

In the longer term, Saudi Arabia will continue the transition to become an effective E-Government. In turn, will seek and improve IT to support the economic and population growth. The development of "Smart cities" today will make it easy to deploy the content and the solutions of smart G2C in the future. The proposed application provides and offers the advices, support and services that citizen's need in different sectors. Evaluate the way of communication with citizens and provides recommendations for enhancements. The primary goal of this application is to enhance the quality and quantity of services available to citizens. A valuable source of services and contact information. Notifications to receive daily content updates. Services delivered to citizens faster, and at a lower operating expense [14].It helps citizens to find better solutions, and make their life simpler, by improving the collaboration between all governments and the coordinated community response to citizen's needs, and by providing high-quality services that met and solve the individual needs of citizens. Receive advices and consults from participation on this application, to get wealth of content across different sectors. In this application, a new source can be added of profit, we can take advantage through the addition of advertisements or by providing the services in exchange for money. Deploy our application on social networks because it is the ideal platforms to support our application. Superiority to our competitors having one platform that offer the combination of most government services. We are looking to apply it in Jeddah city first, that can enhance our position and give us an important advantage for our competitors. Our vision is to provide Jeddah individuals with as many options as possible so everyone can find the government services that best fits their unique needs.

\section{B. Implementation barriers of E-Gov application}

There are always some barriers against new application or technologies. Here some expected barriers that may face the application implementation from different perspective:

- Community Not Engaged or at the Same Readiness

The Smart City still face some obstacles in Saudi Arabia community that they haven't engaged enough and they are not at the same level of readiness as other community like USA or Europe countries. This barrier is very important of smart city evolution because there are really some of community don't recognize this and elect not to engage with technology. Also, there are people still prefer traditional methods to perform government transaction and don't feeling good if they change their tasks that they familiar to do it in some way to another totally different way.

Smart cities application challenged by lack of clarity around the benefits initiative would bring. They need better resources, tools, guidance, and expertise to help them understand what a smart city application could do for their community.

- Infrastructure.

There is interoperability between different technology areas in Saudi Arabia. Also, the internet connection here is very primitive and doesn't cover all city and villages so that there are still people can't involve with this application.

- Data Security and Privacy

Data is always a problem in any technology endeavor, making policies around data security is very critical. Especially with this kind of application that contains personal information with location determination.

\section{CONCLUSION}

It is no longer enough for the traditional government to adapt to the change, but it is necessary to radically reconsidered its model and create a completely new model. E-government is a revolutionary solution in all areas of public administration. The e-government supports traditional government processes in terms of providing automated services to the public of beneficiaries and their participation in decision-making to achieve greater transparency in the governance process. It also aims maintain high levels of quality and to contribute in improving the national economy and improve the image of the country in general as well as serve the most essential element in the community is the citizen. E-Gov has been designed and developed to satisfy this goal. In the future, we will increase the number of ministries associated with this application and we will apply it in all cities after studying the problems we will face while implementing it in Jeddah. This application also improves communication between citizens and other ministries 
IARJSET

and between citizens to citizens, it also responds in a timely manner to citizens and takes assessment and reaction from citizens for improvement. Timely access to any valuable information, warnings and data at anytime and anywhere. They will receive email and SMS notification every time when they transaction has done and [11] [10]. They can also pay for the services that done by money using mobile, Debit Cards and online banking from local banks. They can also fill the application forms online, submit it and finally receive your permit in PDF format from wherever you are. We hope to make government services improve and then improve the outcome and to achieve the aspirations of Jeddah citizens and their satisfaction with our application.

\section{ACKNOWLEDGMENT}

This paper was supported by King Abdul-Aziz University, Saudi Arabia. We thank our supervisor Dr. Maram Meccawy from KAU who provided insight and expertise that greatly assisted the paper.

\section{REFERENCES}

[1] J.-S. Hwang, "Smart Cities Seoul: a case study.," Feb 2013.

[2] "smart Cities," The North Sea Region Programme, [Online]. Available: http://www.smartcities.info/.

[3] G. o. I. Ministry of Urban Development, "Smart City Features," $12 \quad 4 \quad 2017 . \quad$ [Online]. Available: http://smartcities.gov.in/content/innerpage/smart-city-features.php.

[4] R. Heeks, "eGovernment for Development," University of Manchester's Institute for Development Policy and Management, 2008. [Online]. Available: http://www.egov4dev.org/success/index.shtml.

[5] C. R. a. N. K. Hans Schaffers, "Special Issue on Smart Applications for Smart Cities - New Approaches to Innovation," Journal of Theoretical and Applied Electronic Commerce Research, vol. 7, no. 3, 2012.

[6] "Absher," [Online]. Available: https://itunes.apple.com/sa/app/ شر/id1004966456?mt=8.

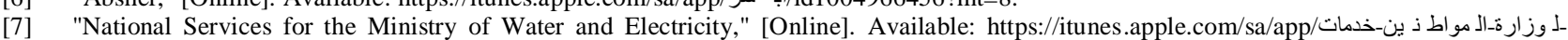
"lid1033017811?mt=8.

[8] "mystc," [Online]. Available: https://itunes.apple.com/sa/app/mystc-app/id808807355?mt=8.

[9] "Ministry of Health," [Online]. Available: https://itunes.apple.com/sa/app/ll/id770058890?mt=8.

[10] "Noor System," [Online]. Available: https://noor.moe.gov.sa/NOOR/Login.aspx. [Accessed 12 may 2017].

[11] "Safeer for students," [Online]. Available: https://safeer.moe.gov.sa/Sites/Student/Pages/default.aspx. [Accessed 12 may 2017].

[12] "e-solutions," [Online]. Available: https://www.moe.gov.sa/en/Pages/default.aspx. [Accessed 552017$].$

[13] "gov.uk," [Online]. Available: https://www.gov.uk. [Accessed 5 2017].

[14] N. Baird, Smart Cities Of The Future In Asia:The Opportunities For UK Business, London: UK Trade \& Investmen, 2012. 